\title{
Challenges and Features of Warehousing Operations With Respect to Logistics Warehouse Companies in Chennai
}

\author{
V.Sivakumar, R.Ruthramathi
}

\begin{abstract}
Supply chain processes involved in this like sourcing, transportation, warehousing, inventory management, replenishment, cold chain management. Warehousing is the segment of enterprise logistic functions responsible for the storage space and managing of the inventories beginning with suppliers receipt and ending with the consumption point. Warehouse operations cover a number of significant areas, from the receiving, organization, fulfillment, and supply processes and areas including Receiving of goods, integrating and maintaining tracking software. Goal of warehouse operations is to satisfy customer's desires and necessities whereas utilizing house, equipment, and labor effectively. The current trends and pressures on provide chain and logistics-forever increasing client examine levels, inventory optimization, time solidity and cost minimization have predictably changed the structure of supply chains and the location site and working of warehouses within the supply chains network .Supply Chain Management encompasses scheduling and organization of all activities involved in sourcing, procurement, conversion, and logistics managing activities. The business contains each variety of warehouses and the trendy multi-purpose supply centers furthermore because the ancient storage facilities called godowns.
\end{abstract}

Key words: Logistics, Security, Storage Facilities, logistics services, Warehousing Management, Warehouse operations.

\section{INTRODUCTION}

Warehouse is planned houses for extra space carefully and treatment of boards and material items. "Stockroom and focus dispersion" mutual, managed and effective are the words used in the clarification of the important work main distribution center. Warehousing and setting are two totally different parts of equivalent capacity in interims chain arrangement. Warehousing is that the load space reserved to store goods, stocks, information, etc. in a predetermined area or building. A warehouse redesigns and repackages the goods. Item to mostly show up bundled on a larger scale and on a scale bundled leaf littler. In various words, important to do from this distribution center is to inhibit the under bump goliath fabricated products and spread them in a number of littler. In these domains, the downstream distribution center activities are generally more concentrated work. This is yet more original when the item is handled as a landscape. When all is said in done, use a littler of dealing with the unit, the greater handling fees. Despite the fact that the distribution center will serve really various closures, most offer a common example of a flow texture indistinguishable. Basically, they get a bulk delivery, set them to fast healing;

Revised Manuscript Received on 14, October 2019.

Dr. V.Sivakumar, Associate Professor, Department of Logistics Management, Alagappa University, Karaikudi, Tamilnadu, India.

R.Ruthramathi, Research scholar, Department of Logistics Management, Alagappa University, Karaikudi, Tamilnadu, India. at that time, because of the demands of the client, recover and sort of SKUs, and send them to clients and offer the chain could be the composition of the association, gathering, innovation, practice, in the grouping and the assets concerned in moving items or administration of the operator to the buyer, store system, traders, transporters, warehouses and providers that participate in the generation, conveyance and exchange manage items to customers. These exercises are identified with the flow and change and modify items from the raw material stage to the client on, such as assetrelated data and the river. Exercise network inventory asset revise characteristics, the raw teeth and parts are becoming more and finished with the item being delivered to the end client. In simple terms, is a network inventory or business relationship between the company and the provider and the client. Event production network of warehouses that are also mentioned as coordinating the collection, consisting of providers, the focus of the industry, distribution centers, the focus of rationing, and retail outlets, as fit as raw materials, stocks of work-in-process, and over and done with items that are streaming between administrations.

\section{RESEARCH OBJECTIVES}

1. To identify the various types of goods stored in warehouse.

2. To investigate the major challenges faced by warehouse operators.

3. To know about the feature development of warehouse supply chain operations.

4. To offer the suggestions to improve the warehouse efficiency.

\section{REVIEW OF LITERATURE}

This investigation proposes expanding the judicious primary angles associated with distribution center plan with outline development that uncovers condition ofworkmanship. Book reference early examinations yielded skeletons stockroom structure, the very much considered in three measurements: input; planning and execution plan; and one yield. The examination covers the primary perspectives adorned in scholastic writing that affected the plan of the distribution center. In a distribution dependent on hypothetical/observational and quantitative methodologies/subjective shows. Then again, with the systematization zone distribution center plan; scientists had the option to distinguish holes that could bring about future

Published By:

Blue Eyes Intelligence Engineering

\& Sciences Publication

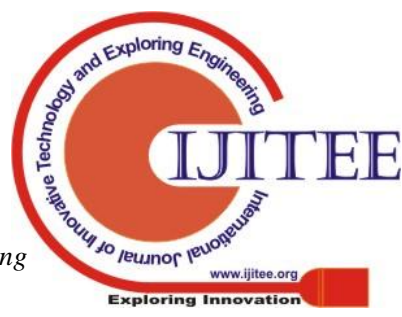




\section{CHALLENGES AND FEATURES OF WAREHOUSING OPERATIONS WITH RESPECT TO LOGISTICS WAREHOUSE COMPANIES IN CHENNAI}

considers [1] The report expressed that the Indian business long have disregarded the significance of the coordinations segment which keeps on staying one of the most under put area in this nation. While the distribution center market wasteful aspects in overseeing it can prompt extreme disturbances all through the production network arrange. In India, the aptitude identifying with the areas as of now not very reassuring, on the grounds that it brought about exceptional misfortunes all through the transportation, dispersion and capacity of the item. Today, given the generous development in sorted out retail and generation exercises in the Republic of India, the market affidavits have a bit by bit picking up steam in the interim cycle gave that each drove interest to warehousing, consequently giving a lift Brobdingnagian to the basic market [2] issues are partitioned into a few gatherings, First, the structure of a significant industry of the issues spoke to stockroom. Second, the nature of operational and auxiliary structure of the Company Repositioning denoted, that in extraordinary thought during this work. Third, coordinative and prevailing framework for stockroom tasks are quickly referenced, and the activity of run of the mill sharp repositioning of the zone structure spoke to specialized and operational units. The primary target of this paper is to show the best in class in streamlining considered three groups that attract the stockroom supply and circulation focuses [3] In the examination work to listen cautiously to improve the proficiency of the efficiency of request picking and client pick and staggered rack stockpiling distribution center conveyance through the application. Distribution center productivity is deciding the fitting stockpiling area for conceivably a huge number of items in the stockroom. Different factors piercing capacity errands, for example, designing so as to pick the size and format of the capacity frameworks, material taking care of frameworks, item qualities, request patterns, turnover rates and lodging needs ar contemplated widely. Has taught that an arrangement of capacity undertakings got (ie arbitrary, committed or classbased) strategies and directing (ie transverse, back or joined) related with a higher factor might be the appropriate response that should be possible to expand the potential [4] report how organizations must deal with the arranging and control exercises identified with the capacity stockroom framework in this day and age of quickly changing interest of clients, a little web orders, tight conveyance plans and a high assistance level necessities. Surveys of reporting is the first to clarify the current, conventional arrangement of arranging and control in the stockroom framework, and afterward with another way to deal with dealing with the arranging and control approach progressively productive and decrease the reaction time to keep up the presence of a distribution center in this day and age of quickly changing client request. The investigation finishes up with a resultant arranging related exercises and are urged to place more exertion in the improvement of new models, rather than upgrading existing [5] decisions made by the capacity units ought to consider the whole store network from the provider to the end customer. This requires a profound comprehension regarding how the different components and exercises are incorporated [9,10,11,12,14,15]

Research Method
A structured quantitative studies in May 2019 which consists of 11 questions. It is isolated into 4 segments: 1) socio-economic Respondents; 2) types of merchandise to get rid of the warehouse in Chennai; 3) The challenge looked after by the administrator of distribution centers and 4) the activity of the normal distribution centers and highlights from the distribution center. Exploration instrument is in any case initially directed at a small sample of the owner of the warehouse and some minor changes done. This picture is managed utilizing online reviews apparatus. By 118 prospective members must be online picture and after the expulsion of the reaction can not be used, for example 91 members was held.

\section{FINDINGS AND DISCUSSION \& RESULTS}

Examples consist of more people (89 percent) than women members (11 percent) as the number of male respondents more prominent than female respondents. The age of respondents was profound went from 31 to 40 (58.2Percent). In addition, the level of most members of this Appointment Delivery Specialist (37.4 percent) and the owners (24.2 percent) and 25.3 percent of this member Executive Employees, material handler (13.2 Percent) the results are shown in Table 1 ,

Table-1. Demographic profile of the respondents

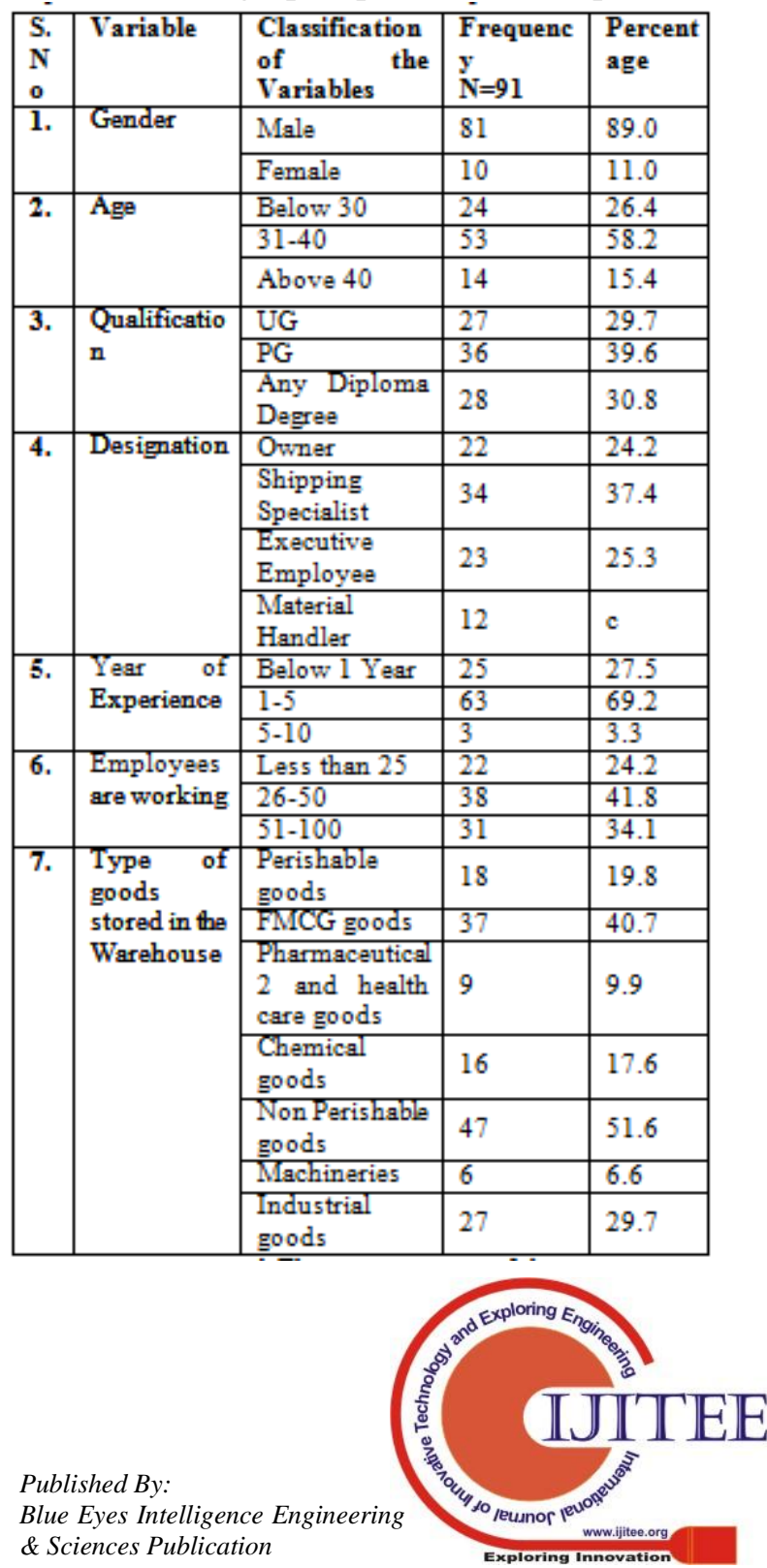




\section{Hypothesis:}

There is no significant difference between connecting the Challenges of warehouse operators and designation factors.

Various factors are discussed among the respondents for Challenges of warehouse operators and designation factors. Challenges of warehouse operators in Managing Warehouse Space/Layout,

Customer Expectations,

Redundant
Processes, Product Diversification, Product Picking Optimization, Inventory Accuracy/ Tracking, Time Management, Fire Accident, Labour workforce, Communication. These functions are challenges of warehouse operators in the different factors of different designation of warehouse operators Owner, Shipping Specialist, Executive Employee, and Material Handler.

Table-2. Difference between Challenges of warehouse operators and designation factors

ANOVA

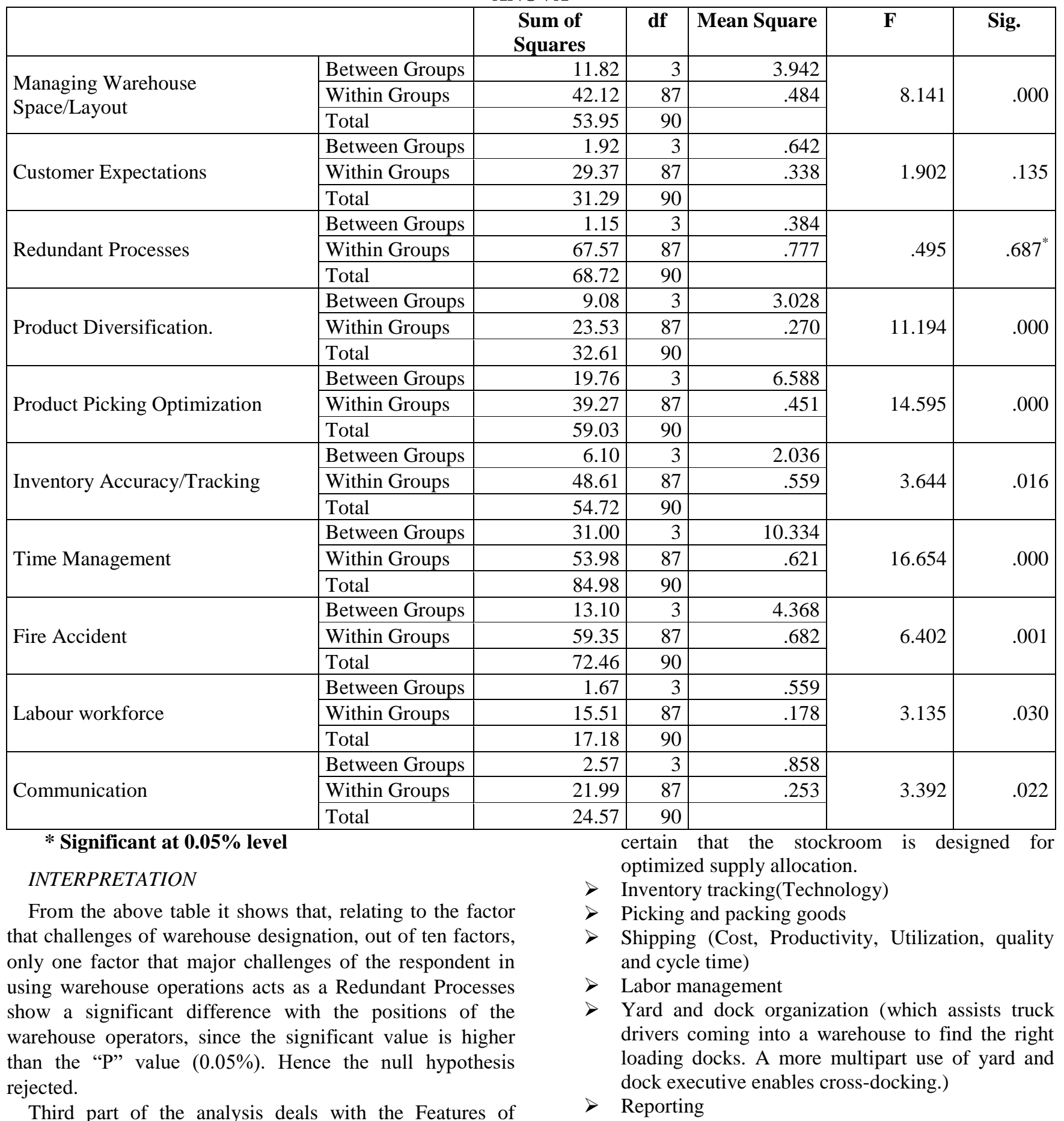

Third part of the analysis deals with the Features of warehouse management operations and the level of respondents about the various applications which are designed to enhance the user's skills in different ways. Many applications are identified through the review and listed in the study. They are as follows:

$>$ Warehouse design which enables organization to customize workflow and alternative logic to create 


\section{CHALLENGES AND FEATURES OF WAREHOUSING OPERATIONS WITH RESPECT TO LOGISTICS WAREHOUSE COMPANIES IN CHENNAI}

Figure1: Features of warehouse management operations

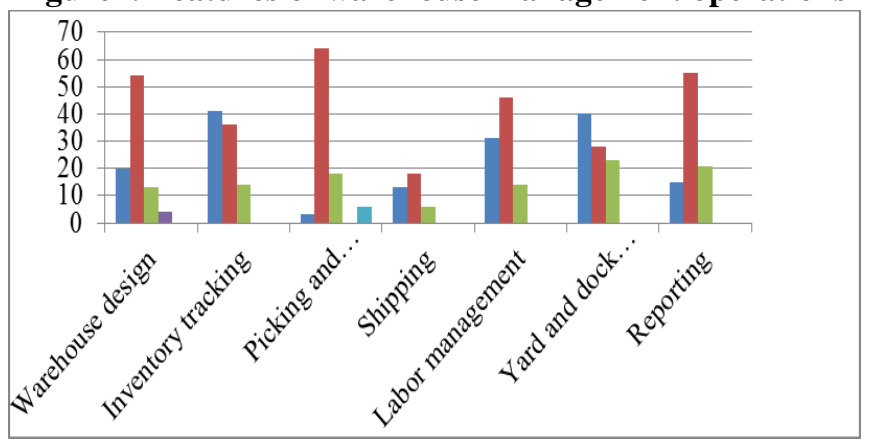

Figure 1 outlines the operational highlights of the stockroom the board. Among the highlights recorded, respondents had every one of the applications and use levels likewise contrast by person.

The last piece of the examination manages an alternate movement at the distribution center highlights that can exploit the advancement of the stockroom. Different exercises, for example, Warehouse Management Systems set opening container which expands extra room and record for differences in occasional stock. the quest for cutting edge frameworks, including Radio-Frequency Identification (RFID), Automatic Identification and Data Capture (AIDC) and standardized identification scanners to guarantee that the merchandise can be found effectively when they need to move. Conveyance empowers Warehouse Management System to send the bill-of-filling (B/L) preceding load, seed pressing rundown and receipt for delivery and send advance transportation notification to beneficiaries. detailed that assists administrators with dissecting performing distribution center activities and the warning zone to increment.

\section{SUGGESTIONS}

Distribution center framework includes strength, consistency and inward controls for techniques to serve for you progress through your stockroom stock most speed, up to each phase of satisfaction strategy. Picking and pressing products defensive material to improve the working of the stockroom picking zones like the locale, area and bunch picking waves. Distribution center staff can even utilize sectionalization load and errand interleaving capacities to manage the assignment of pick-and-pack in the most ideal manner. Actualize and keep up techniques for taking care of products in distribution centers viably and effectively to dispense with the difficulties of the stockroom administrator. Associations attempting to create to improve the presentation of their store network to turn out to be increasingly compelling and productive.

\section{CONCLUSION}

The conduct of the store network and the substance turns into a huge requirement for the association of stockroom coordinations. Distribution center that offers some incentive included chain through the accessibility of the products at the correct time and the ideal spot.Warehouse the executives framework, the time has come to consider the careful needs of the stockroom. Beginning with manipulative inbound and outbound recurrence items. Chances to improve stockroom tasks, intelligence among exercises and fitting choices. Among those highlights are the immediate control of the capacity of store distribution center space, simple correspondence with further pieces of the inventory network and the elevated level of robotization. Appraisal is a procedure that assesses the activity of the ten classifications of execution in the stockroom. Classes in client assistance tasks evaluation, control frameworks, stock exactness, work profitability, the format of the office, wellbeing.

\section{REFERENCE}

1. Augusto da Cunha Reis(2017), distribution center plan, an orderly writing survey, Brazilian Journal of Operations and Production Management 14 (2017), pp 542-555, ABEPRO

DOI:

10.14488/BJOPM.2017.v14.n4.a10

2. Knight Frank (2014), India Logistics and Warehousing Report, http://content.knightfrank.com/inquire about/677/archives/en/india-warehousing-andcoordinations report2326.pdf

3. Jan Kara's (2013), An Overview of Warehouse Optimization, International Journal of Advances in Telecommunication Electro methods, Signals and Systems, Volume No.2, issue No.3.

4. Felix T.S. Chan, H.K. Chan (2011), Improving the efficiency of request picking of a manual-pick and staggered rack dissemination distribution center through the execution of class-based stockpiling, Expert Systems with Applications, Volume No. 38, Issue No.3, PP. 2686-2700

5. Jochem Springer's (2010), Planning and control in stockroom frameworks, Bachelor Thesis Organization and Strategy, Premaster Operations the executives and Logistics. ANR: 860755 http://arno.uvt.nl/show.cgi?fid=121828

6. Sahar Elbarky (2016), Warehousing Risk Management in Different Industrial sixth International Conference on Information Systems, Logistics and Supply Chain (ILSInternational Conference)

7. 7. Augusto da Cunha Reis(2017) WAREHOUSE DESIGN: A SYSTEMATIC LITERATURE REVIEW Brazilian Journal of Operations and Production Management 14 (2017), pp 542-555 , DOI: 10.14488/BJOPM.2017.v14.n4.a10

8. Juri Kondratjev (2015) Logistics. Transportation and distribution center in store network

9. Baker, P. (2004), "Adjusting Distribution Center Operations to Supply Chain Strategy", The International Journal of Logistics Management, Vol. 15, No. 1, pp. 111-123.

10. Chow, H. K. H. et al. (2005), "Structure of an information based coordinations procedure framework", Expert Systems with Applications, Vol. 29, No. 2, pp. 272-290.

11. Gill, A. (2009), "Deciding stacking dock prerequisites underway conveyance offices under vulnerability", Computers and Industrial Engineering, Vol. 57, No. 1, pp. 161-168.

12. Koster, R. et al. (2007), "Structure and Control of Warehouse Order Picking: A Literature Review", European Journal of Operational Research, Vol. 182, No. 2, pp. 481-501.

13. Tompkins, J. A. et al. (1996), Facilities Planning, 2th ed., Jonh Willey, New York 
14. Cordeau, J. F. et al. (2006), A coordinated model for coordinations arrange structure, Annals of Operations Research, Vol. 144, No. 1, pp. 59-82

15. Demirel, T. et al. (2010), "Multi-criteria distribution center area choice utilizing Choquet fundamental", Expert Systems with Applications, Vol. 37, No. 5, pp. 3943-3952.

16. http://iosrjournals.org/iosr-jbm/papers/Vol15issue6/I01566066.pdf

17. https://www.researchgate.net/production/50946316_UN DERSTANDING_OF_SUPPLY_CHAIN_A_LITERAT URE_REVIEW

18. https://www.academia.edu/27435107/Supply_Chain_Ma nagement_Literature_Review_and_Some_Issues

19. https://www.researchgate.net/production/322820208_A Literature_Review_on_Performance_Measures_of_Logis tics_Management_An_Intellectual_Capital_Perspective

\section{ACKNOWLEDGEMENT}

The authors thank the RUSA Phase 2.0 Grant (No: F.24-51/2014-U. Policy (TN. Multi-Gen). Dept. Of Edn. Govt. of India dated 09.10.20118) Scheme of MHRD, Govt of India.

\section{ABOUT THE AUTHORS}

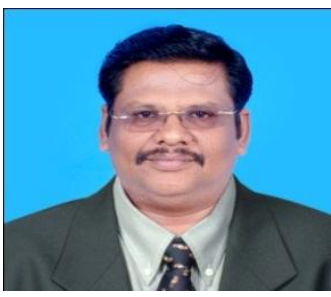

Dr. V. Sivakumar is the first autho of this research article. $\mathrm{He}$ is an accomplished marketing professor with comprehensive blend of academic experience and research knowledge in the field of agricultural marketing. His field of expertise extends to variety of inter related areas such as marketing, consumer behaviour, tourism and hospitality research, logistics and supply chain management.

Degree: B.E (Agri), M. B. A, M. Phil, PhD

E-mail: sivakumarv@alagappauniversity.ac.in

As an innovative teacher devoted to education and learning, he also made a lot of scholarly contribution and published more than 40 research papers in international and national journals.He is currently working as the Department of Logistics Management, Alagappa University.

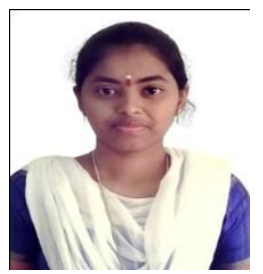

Ms.R.Ruthramathi is the Second author of this research article. She is a pursuing her research in the area of Logistics Management, Alagappa University.

E-mail: ruthramathi06@gmail.com 